2 Lewis D, Moore C, Morrissey P, Leikin J. Determination of drug exposure using hair: application to child protective cases. Forensic Sci Int 1997;84:123-8

3 Strano Rossi S, Offidani C, Chiarotti M. Application of hair analysis to document coercive heroin administration to a child. J Anal Toxicol $1998 ; 22: 75-7$

4 Vinner C, Vignau J, Thibault D, et al. Hair analysis of opiates in mothers and newborns for evaluating opiate exposure during pregnancy. Forensic Sci Int 2003;133:57-62

5 Vinner E, Vignau J, Thibault D, et al. Neonatal hair analysis contribution to establishing a gestational drug exposure profile and predicting a withdrawal syndrome. Ther Drug Monit 2003;25:421-32

6 Skopp G, Pötsch L. A case report on drug screening of nail clippings to detect prenatal drug exposure. Ther Drug Monit 1997;19:386-9

7 American Academy of Pediatrics, Committee on Drugs. Transfer of drugs and other chemicals into human milk. Pediatrics 2001;108:776-89

8 The Children Act 1989. London: HM Stationery Office, 1989

\section{Neonatal pleural effusion and insertion of intercostal drain into the liver}

\author{
M J Murray MA MRCPCH ${ }^{1} \quad J$ L Brain MS FRCS ${ }^{2}$ \\ J S Ahluwalia FRCP FRCPCH ${ }^{1}$
}

J R Soc Med 2005;98:319-320

When a congenital diaphragmatic hernia $(\mathrm{CDH})$ is leftsided, radiographic diagnosis is usually straightforward. Right-sided $\mathrm{CDH}$ is clinically and radiographically more difficult.

\section{CASE HISTORY}

Dichorionic twins, a girl (twin 1) and a boy (twin 2), were born at 37 weeks by emergency caesarean section for prolonged rupture of membranes and fetal tachycardia in twin 1 . At first they were in good condition but at ten hours of age twin 2 developed signs of respiratory distress with mild hypercapnia $\left(\mathrm{pCO}_{2} \quad 7-8 \mathrm{kPa}\right)$ but no significant acidosis. A chest radiograph showed infiltrative changes in the right middle and lower lobes with the diaphragm apparently normal (Figure 1). Because the infant was irritable on handling, lumbar puncture was performed in addition to a partial sepsis screen. Antibiotics were given and the respiratory distress settled in forty-eight hours

Departments of ${ }^{1}$ Neonatology and ${ }^{2}$ Paediatric Surgery, Addenbrooke's Hospital Cambridge, UK

Correspondence to: Dr J S Ahluwalia, Neonatal Intensive Care Unit, Box 226, Addenbrooke's Hospital, Hills Road, Cambridge CB2 2SW, UK

E-mail: jag.ahluwalia@addenbrookes.nhs.uk without respiratory support. C-reactive protein peaked at $89 \mathrm{mg} / \mathrm{L}$ on day 4 and was normal by day 7 ; all cultures were subsequently reported negative. Twin 1 , who likewise received antibiotics, had a raised $\mathrm{C}$-reactive protein and group B streptococcus was grown from surface swabs.

On day 9 twin 2 became severely distressed with tachypnoea and a respiratory acidosis $\left(\mathrm{pCO}_{2} 10 \mathrm{kPa}\right)$. The chest radiograph (Figure 2) showed complete opacification of the right hemithorax consistent with a pleural effusion. In addition the nasogastric tube was noted to deviate to the left at the level of the mid-oesophagus. The infant was placed on continuous positive airway pressure with supplemental oxygen. An intercostal drain was inserted at the fourth intercostal space in the mid-axillary line and $27 \mathrm{~mL}$ clear serous fluid was obtained. When the drain ceased to show respiratory swings but clinical signs persisted, $20 \mathrm{~mL}$ of clear fluid was removed by thoracocentesis. The chest radiograph now revealed a liver shadow and bowel gas in the right hemithorax (Figure 2). An ultrasound scan, likewise indicating that the liver was in the right hemithorax, suggested that the intercostal drain was embedded in the right lobe of the liver. The infant was then transferred to the regional neonatal surgical centre with the chest drain in situ. On arrival he was intubated and mechanically ventilated. CT confirmed that the intercostal

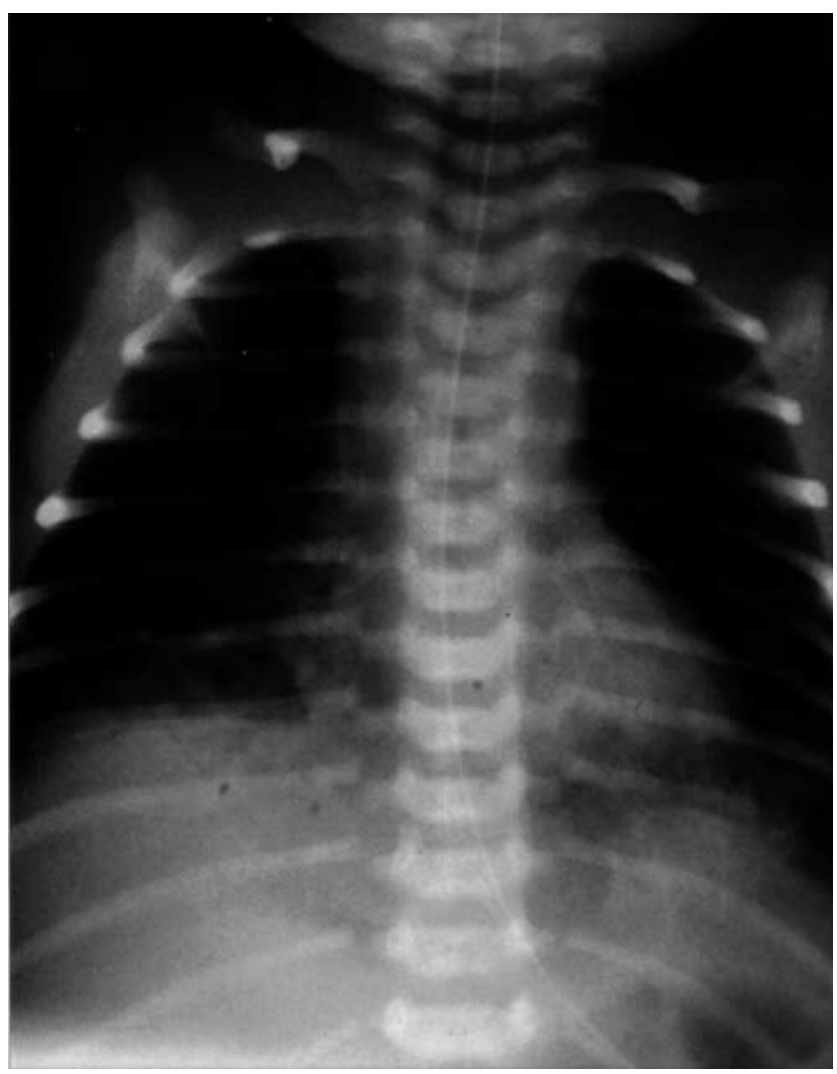

Figure 1 Initial chest radiograph showing infiltrative changes in the right middle and lower lobes with normal diaphragmatic appearance 


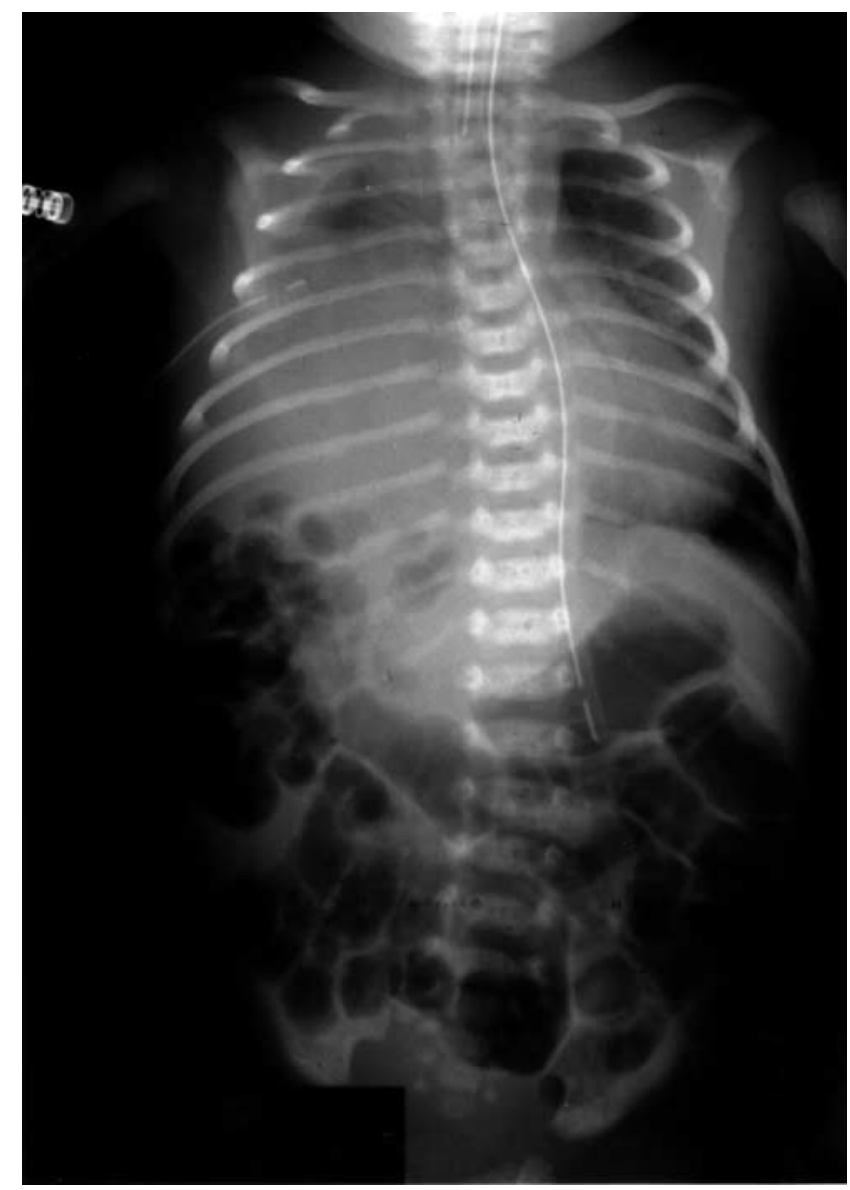

Figure 2 Chest radiograph following insertion of chest drain, showing partial drainage of the pleural effusion. The liver shadow and bowel gas are now seen in the right hemithorax

drain was in the liver. At operation on day 11 the liver and bowel contents were returned to the abdomen and a small defect in the centre of the right diaphragm was repaired. He recovered without incident.

\section{COMMENT}

We suspect that both twins initially had group B streptococcal sepsis. In twin 2, herniation of liver and bowel through the diaphragmatic defect (perhaps intermittent ${ }^{1,2}$ ) then caused the pleural effusion by obstructing hepatic venous outflow and causing transudative weeping from the liver surface. The rapid onset of respiratory distress at day 9 was presumably due to the combined effects of the hernia and the effusion.

This is not the first report of accidental insertion of an intercostal drain into a baby's liver when radiological appearances have suggested pleural effusion or pneumothorax. ${ }^{3-5}$ One lesson of this case, which fortunately ended happily, is that a previously normal chest radiograph does not preclude the diagnosis of a delayed presentation of mediastinal shift, as seen here with the feeding tube, must be taken seriously. These observations are not new: indeed, more than 20 years ago Akierman and Maycock ${ }^{2}$ proposed that congenital diaphragmatic hernia should be considered in exactly these circumstances - when early-onset group B streptococcal infection is followed by a period of improvement and then increased respiratory distress, right-sided pleural effusion and partial or complete opacification of the right side of the thorax associated with mediastinal shift to the left.

\section{REFERENCES}

1 Kirchner SG, Burko H, O'Neill JA, et al. Delayed radiographic presentation of congenital right diaphragmatic hernia. Radiology 1975; 115:155-6

2 Akierman AR, Maycock DE. Group B streptococcal septicemia and delayed-onset congenital right-sided diaphragmatic hernia. Can Med Assoc J 1983;129:1289-90

3 Chilton HW. Right-sided congenital diaphragmatic herniae presenting as pleural effusions in the newborn: dangers and pitfalls. Arch Dis Child 1978;53:600-3

4 Khwaja MS, Al-Arfaj AL, Dawoodu AH. Congenital right-sided diaphragmatic hernia: a heterogeneous lesion. $J R$ Coll Surg Edinb 1989;34:219-22

5 Elhalaby EA, Abo Sikeena MH. Delayed presentation of congenital diaphragmatic hernia. Paediatr Surg Int 2002;18:480-5

\section{Spontaneous liver rupture in Ehlers-Danlos syndrome type IV}

\author{
Siew Chien Ng MRCP ${ }^{1}$ Paolo Muiesan MD²
}

Ehlers-Danlos syndrome type IV can escape diagnosis until the development of catastrophic complications in adult life.

\section{CASE HISTORY}

A Pakistani woman aged 23 years experienced sudden chest pain and dyspnoea five days after caesarean section. Physical examination, chest radiography and arterial blood gas measurements showed nothing abnormal. She was anticoagulated for risk of thromboembolic disease. Six hours later she reported right subscapular pain; her abdomen was

Departments of ${ }^{1} \mathrm{Hepatology}$ and ${ }^{2} \mathrm{Hepatobiliary}$ Surgery, King's College Hospital, Denmark Hill, London SE5 9RS, UK

Correspondence to: $\mathrm{Dr} \mathrm{S} \mathrm{C} \mathrm{Ng}$

E-mail: siewchienng@yahoo.co.uk 